\title{
CARACTERIZAÇÃO DE COBERTURAS INCONSOLIDADAS NA REGIÃO NORTE DE CAMPINAS -SP
}

\author{
Marina Nicoletti Simplicio ${ }^{(a)}$, Jeferson de Lima Picanço ${ }^{(b)}$ \\ (a) Instituto de Geociências, Universidade Estadual de Campinas, marinansimplicio@ gmail.com \\ (b) Instituto de Geociências, Universidade Estadual de Campinas, jeffpicanco@gmail.com
}

\section{EIXO TEMÁTICO: GEOGRAFIA FÍSICA E DESASTRES NATURAIS}

\begin{abstract}
Resumo
A caracterização de materiais inconsolidados é um aspecto importante dos mapas geotécnicos. São mapas fundamentais, dos quais podem surgir mapas de síntese e mapas interpretativos mais sofisticados. O presente trabalho consiste na análise dos regolitos proveniente das rochas encontradas na região de Sousas, localizada no distrito de Campinas-SP. A metodologia empregada consiste no levantamento de informações através de mapas, cartas e imagens de satélites, com o auxílio de campo. A análise e a compilação dos dados da área permitiram a diferenciação de sete unidades básicas e com isso a confecção de um documento cartográfico preliminar de materiais inconsolidados na escala de 1:25000. A proposta do trabalho visa gerar contribuição para o estudo da área assim como informações para pesquisas futuras.
\end{abstract}

Palavras chave: cartografia geotécnica, mapa de materiais inconsolidados, uso e ocupação do solo.

\section{Introdução}

No âmbito da cartografia geotécnica, o mapa de materiais inconsolidados é um dos mapas mais importantes. O mapa de materiais inconsolidados é um dos produtos do mapeamento geotécnico que tem como característica abordar aspectos como origem, textura, espessura e cobertura do manto de alteração dos materiais, caracterizando o regolito, material presente acima da rocha sã até a superfície (Zuquette \& Gandolfi, 2004). Trata-se de um mapa fundamental, em geral derivado dos mapas de solos e do mapa geológico e amparado por investigações de campo. De acordo com estes autores, os materiais inconsolidados influenciam diretamente na eficiência do uso e ocupação do solo e na sua distribuição espacial, sendo utilizados nos mapas derivados e interpretativos subsequentes, como cartas interpretativas (fundações, rejeitos, etc.), em cartas analíticas básicas ou cartas de procedimentos e prognósticos. Estas unidades costumam ser descontínuas, com diferentes espessuras, formando pacotes com formas, posição no espaço e idades variadas além de estarem diretamente ligados à interação dos materiais geológicos e os processos naturais. 


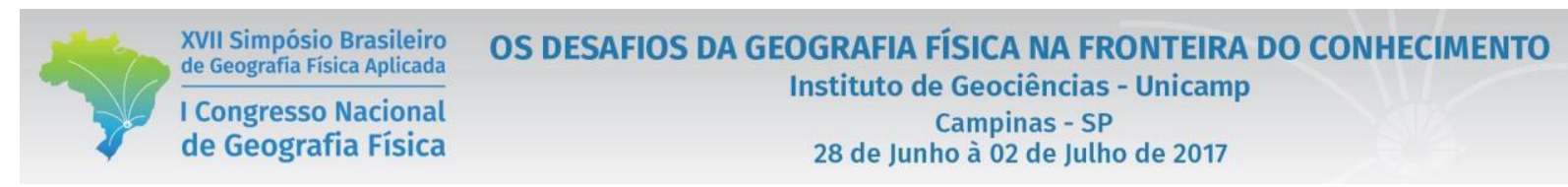

Essas características podem variar bastante ao longo de uma área, portanto, o mapa de material inconsolidado pode conter um grande número de unidades, sendo preciso assim um detalhamento maior comparando a um mapa geológico. Segundo estes autores, a separação das unidades pode ser feita com o auxílio de uma árvore lógica a qual é dividida em vários atributos (Figura 1).

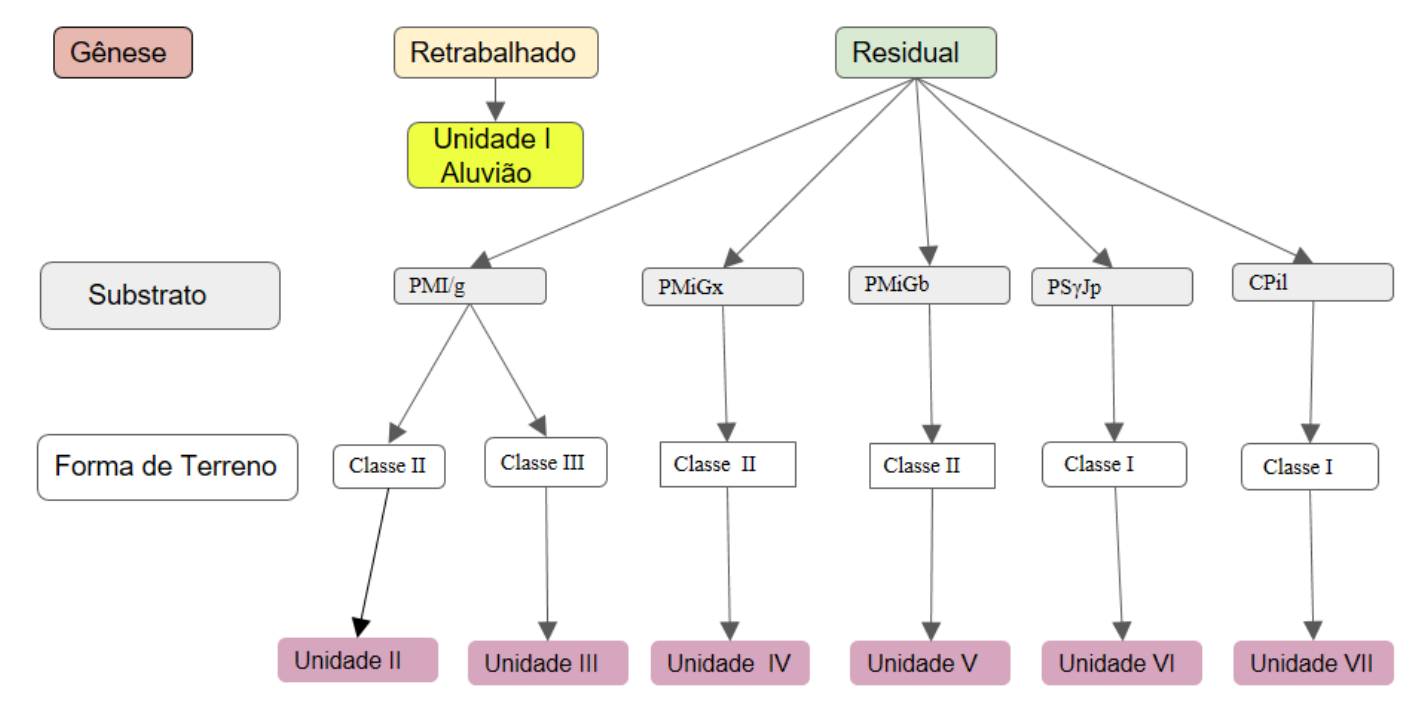

Figura 1: Árvore lógica utilizada para determinar unidades no mapa.

A região ao norte do município de Campinas, estado de São Paulo é uma área de grande potencial para o crescimento urbano. O presente trabalho visa a caracterização preliminar de materiais inconsolidados na região. O objetivo do estudo é confeccionar um mapa na escala de 1:25000 através da análise morfológica-geomorfológica, utilizando o mapa geológico, pedológico e geomorfológico.

\section{Materiais e Métodos}

O mapa de materiais inconsolidados é obtido a partir do cruzamento de mapas básicos (geologia, declividade, Formas do Terreno). Os principais mapas utilizados na análise foram os mapas geológico (IG, 1993) na escala de 1:50.000, pedológico (Valladares et al, 2008) na escala de 1:50.000 e geomorfológico (Campinas, 2006) na escala de 1:50.000. O mapa topográfico e a declividade foram obtidas com o uso de modelos digitais de elevação $(30 \mathrm{~m})$ do projeto Topodata (Valeriano et al, 2011), construídos em ambiente GIS. Também foram utilizadas imagens do Google Earth PRO e imagens de satélite. Além disso, a pesquisa contou com trabalho de campo realizado na região. 
O mapa de materiais inconsolidados em escala de 1:25000 foi construído com auxílio do Software Arcgis 10.4. O método utilizado para a separação das unidades corresponde a árvore lógica (Zuquette \& Gandolfi, 2004), a qual considera os diferentes tipos de materiais inconsolidados tanto no caráter qualitativo quanto no quantitativo em relação aos regolitos, levando em conta um certo número de atributos, como gênese do material, substrato rochoso e forma de terreno.

\section{Resultados}

A Figura 1 apresenta de forma esquemática a árvore lógica utilizada para definir as unidades, mostrando as características levadas em conta para a separação de unidades. O primeiro nível da árvore corresponde a gênese do material, dividida em materiais residuais e retrabalhados. Os materiais residuais correspondem a aqueles que estão in situ enquanto que os materiais retrabalhados são aqueles que por algum motivo sofreram transporte, sendo divididos em origem aluvionar ou coluvionar. $\mathrm{Na}$ área estudada foi obtida somente uma unidade (Unidade I) de origem retrabalhada, sendo aluvionar. Esta unidade ocorre nas calhas das principais drenagens que cortam a área, com uma espessura de poucos metros ( 0 a $3 \mathrm{~m})$.

O Segundo nível da árvore leva em conta somente os materiais de origem residual. A etapa diferencia o substrato rochoso, ou seja, faz a separação através das características litológicas mais representativas. $\mathrm{Na}$ área do trabalho foram encontradas as seguintes litologias: gnaisses xistosos (PMiGx), gnaisses bandados (PMiGb), Granitos gnáissicos (PMI/g), hornblenda-biotita granitos (PS $\gamma \mathrm{Jp}$ ) e arenito, diamictito, folhelho, ritmito (CPil)

O terceiro nível da árvore corresponde a feições de relevo, que no presente trabalho é dividida em 3 principais classes: colinosos suavemente ondulados (classe I), colinosos ondulados inclinados (classe II) e amorroados de inclinação moderada (classe III). Na separação foram consideradas como uma unidade aquela que apresentou mesma gênese do material, litologia e feições de relevo. O mapa confeccionado apresenta o total de 7 unidades conforme a figura 2 e a Tabela 1. 

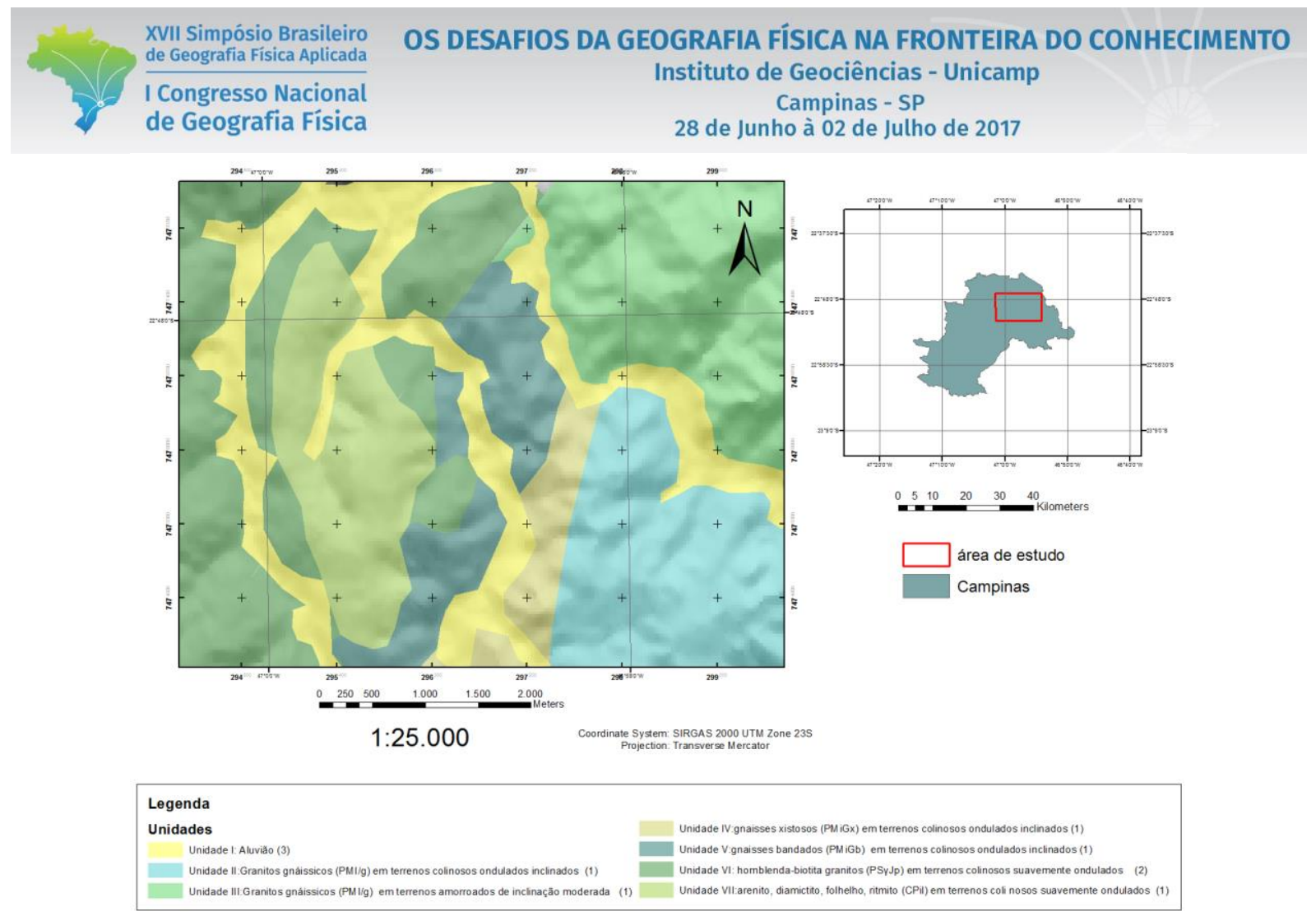

Figura 2: Mapa de materiais inconsolidados.

Tabela 1 - Quadro das unidades do mapa de Materiais Inconsolidados

\begin{tabular}{|c|l|c|l|}
\hline Unidade & \multicolumn{1}{|c|}{ Nome Área $\left(\mathrm{Km}^{2}\right)$} & \multicolumn{1}{|c|}{ Caracteristicas } \\
\hline I & Aluvião & 4,02 & Pouco espesso, areias, cascalhos, argilas \\
\hline II & $\begin{array}{l}\text { Residual granito (PMI/g) relevo } \\
\text { colinoso, ondulados inclinados }\end{array}$ & 3,86 & $\begin{array}{l}\text { Espesso, poroso, com feições reliquiares, } \\
\text { silto-argiloso }\end{array}$ \\
\hline III & $\begin{array}{l}\text { Residual granito (PMI/g) relevo } \\
\text { amorroado de inclinação moderada }\end{array}$ & 1,05 & $\begin{array}{l}\text { Pouco espesso e com feições reliquiares, } \\
\text { silto-argiloso }\end{array}$ \\
\hline IV & $\begin{array}{l}\text { Residual gnaisse (PMiGx) relevo } \\
\text { colinoso ondulados inclinados }\end{array}$ & 3,82 & $\begin{array}{l}\text { Espesso, poroso, com feições reliquiares, } \\
\text { silto-argiloso }\end{array}$ \\
\hline V & $\begin{array}{l}\text { Residual gnaisse (PMiGb) relevo } \\
\text { colinoso, ondulados inclinados }\end{array}$ & 2,41 & $\begin{array}{l}\text { Espesso, poroso, com feições reliquiares } \\
\text { silto-argiloso }\end{array}$ \\
\hline VI & $\begin{array}{l}\text { Residual granitos gnáissicos (PS } \gamma \mathrm{Jp}) \\
\text { relevo colinoso suavemente ondulados }\end{array}$ & 3,26 & $\begin{array}{l}\text { Muito espesso, poroso, homogêneo, silto- } \\
\text { argiloso }\end{array}$ \\
\hline VII & $\begin{array}{l}\text { Residual diamictitos paleozoicos (CPil) } \\
\text { relevo colinoso suavemente ondulados }\end{array}$ & 3,08 & Muito espesso, com seixos, argilas e areia \\
\hline
\end{tabular}




\section{Conclusão}

O presente trabalho resultou em sete diferentes unidades: uma dentro da subdivisão de materiais retrabalhados e seis consideradas materiais residuais. o material retrabalhado compreende o aluvião, que se encontra associado aos rios maiores. Materiais coluvionares podem ser encontrados capeando solos residuais, e não puderam ser individualizados nesta escala. Os materiais residuais são produtos da alteração das rochas, em sua maioria composta por gnaisses e uma pequena parte por arenitos.

A aplicação do método de árvore lógica usado no trabalho mostrou-se eficaz na separação dos materiais inconsolidados. Porém, para uma melhor caracterização e complementação do estudo, contudo, é necessário avaliar as características de espessura, propriedades geotécnicas e geomecânicas das unidades presentes na região.

A fim de se obter um bom mapa de materiais inconsolidados, seria de extrema importância o trabalho de campo, assim como coleta de amostras e ensaios laboratoriais como o ensaio de Sedimentação, Massa Específica, Limite de Plasticidade e Limite de Liquidez. Uma completa caracterização dos materiais inconsolidados é essencial para a análise das potencialidades do solo e através desse conhecimento se faz possível a eficiência no uso e ocupação do norte de Campinas, região que possui um grande potencial para a expansão urbana.

\section{Bibliografia}

CAMPINAS - Prefeitura Municipal de Campinas. Mapa geomorfológico do Município de Campinas, São Paulo, Plano Municipal de Saneamento Básico, Campinas, 2006

INSTITUTO GEOLÓGICO. Mapa geológico do Município de Campinas. São Paulo, 1993, Esc, 1:50.000 (Subsídios do meio físico-geológico ao planejamento do Município de Campinas, SP).

PRANDINI, F. L. et al. Cartas Geotécnicas nos planos diretores regionais e municipais. In: BITAR, O. Y. Curso de Geologia de Engenharia aplicada ao meio ambiente. São Paulo: ABGE, 1995

RODRIGUES, V. P.; AUGUSTO FILHO, A. Mapeamento geotécnico do perímetro urbano e sua área de expansão no município de Jaú-SP: base para o planejamento urbano e ambiental. In: SIMPÓSIO BRASILEIRO DE CARTOGRAFIA GEOTÉCNICA E GEOAMBIENTAL, 6, Uberlândia. Anais... Uberlândia: ABGE, 2007. p. 725-740

VALERIANO, M. M.; ROSSETI, D. F. Topodata: Brazilian full coverage refinement of SRTM data. Applied Geography (Sevenoaks), v. 32, p. 300-309, 2011. 


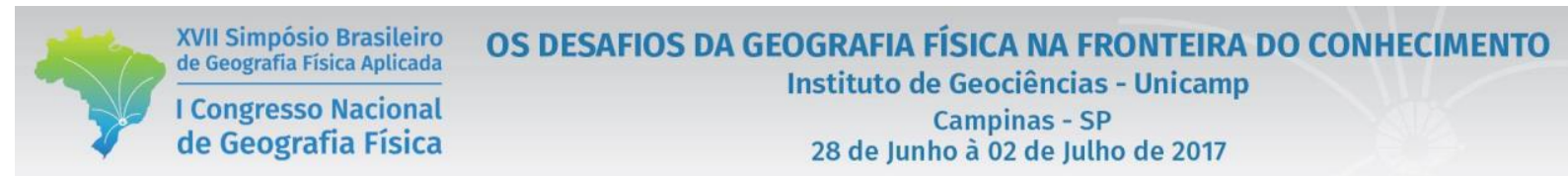

Valladares, G. S.; COElho, R. M.; CHIBA, M. K. Mapa Pedológico do Município de Campinas, SP: Legenda Expandida. Comunicado Técnico, Campinas, Julho de 2008

ZUQUETTE, L. V.; GANDOLFI, N. Cartografia geotécnica. São Paulo: oficina de Textos, 2004. 